Teknomekanik

Vol. 4, No. 1, May 2021, pp. 42 48

e-ISSN: 2621-8720 p-ISSN: 2621-9980

\title{
Optimization of CNC Turning Parameters Using Taguchi Method
}

\author{
Rifelino, Bulkia Rahim and Eko Indrawan
}

Department of Mechanical Engineering, Faculty of Engineering, Universitas Negeri Padang, Padang 25131, Indonesia

\begin{tabular}{l}
\hline Article Info \\
\hline Article history: \\
Received Feb $21^{\text {th }}, 2021$ \\
Revised Mar $19^{\text {th }}, 2021$ \\
Accepted May $02^{\text {th }}, 2021$ \\
\hline
\end{tabular}

\section{Keywords:}

Optimization

Surface Roughness

Taguchi Method

CNC Turning

\begin{abstract}
The surface roughness quality of the machining product plays an important role when it is in contact with other machine components. That quality depends on several parameters setting, such as material, cutting tool, cutting condition and operator skill. This study aims to obtain the optimum setting of turning parameters by using the Taguchi method. Three control factors: cutting speed, depth of cut, and feeding at three different levels are selected. A series CNC turning process on AISI 1045 material were performed using L9 (3) ${ }^{3}$ orthogonal array with cutting fluid. Insert carbide cutting tool is used in the experiment. To reveal the optimum machining parameter, the smaller the better is quality characteristic selected for surface roughness examination of the workpiece. Analysis of experiment results revealed that higher cutting speed, low feed, low depth of cut respectively, provide fine surface quality of the machined workpiece. Moreover, the feed f parameter was found most influence on the surface roughness quality with $53.73 \%$ contribution, cutting speed $v$ provides $23.28 \%$ contribution, and depth of cut a provides $17.87 \%$ contribution. The confirmation experiment shows that level 3 of cutting speed, level 2 of cutting depth, and level 1 of feed deliver the smoothest machined surface of Ra 0,46 $\mu \mathrm{m}$.
\end{abstract}

\section{Corresponding Author:}

Rifelino,

Department of Mechanical Engineering, Faculty of Engineering, Universitas Negeri Padang,

Jln. Prof. Dr. Hamka Air Tawar, Padang 25131, Sumatera Barat, Indonesia

Email: rifelino@ft.unp.ac.id

\section{INTRODUCTION}

The quality of machining product is very important to be taken into account, to be accepted by the market. One of the crucial quality the machining product is surface roughness. Surface roughness is an element of surface texture and plays a key role in determining how the part will associate with its other object. In many engineering applications, the surface finish on a part can have a huge influence on the performance and its endurance. Mostly, the rough of the part surface wear out more often and provides more friction than a smoother surface. Surface roughness is one of the surface qualities of a workpiece that is interesting to explore because many factors influence the result. This quality characteristic is a measure of machined surface quality and a factor that contribute to production cost. Lower roughness indicates a smoother part surface. Besides, it also describes the geometry of the workpiece surface and concatenated with the surface texture.

Various parameters machining parameters affect the result, such as cutting condition, machining ability, tool geometry, cutting tool, material type, lubrication, environment, operator skill, etc [1-5]. The material cutting of machining process, type of cutting tool plays a notable role. The tool must be harder than material, have good toughness, heat and be wear-resistant as well. In terms of meeting the market need about the quality of machining products, therefore, the conditions that contribute to result have to consider. This thing is one of the reasons why smooth machined surfaces require higher production costs.

Metal cutting is one of the most significant manufacturing processes in material removal. Some machine tools apply the cutting by using a single cutting tool, multiple cutting tools, and abrasive tool. Turning is the common process using a single-edge cutting tool. In this process, several cutting conditions such as cutting speed, feed rate, cutting depth, material removal rate, wet or dry machining, workpiece holding mechanism, and so forth [6], still be preferential concerns by the researcher. The high quality of the machined surface is indispensable for some applications in machine construction, which are parts, interconnected with each other. 
Machining parameters have to adapt to various cutting criteria to achieve the optimum result. Taguchi design is a powerful method, which used widely to obtain the optimum adjustment to control factors [6,7]. It technique is reliable to apply in many manufacturing processes. By using an orthogonal array in the design of the experiment, this approach provides low costs investigation because could reduce the number of experiments. The comprehensive quality strategy maintains robustness into the yield of the process during its design stage. Developed by Genichi Taguchi, this method is also called Robust design, which means the system performance able to survive or overcome unfavourable conditions. In addition, allows detecting the appropriate control factor levels in a design of experiment to make the system minus sensitive to noise factors.

Some researchers applied the Taguchi approach in the machining study, with concern to tool wear prediction [8], various cutting fluid conditions [3], and material removal rate analysis [9]. Baharudin, et al [10] investigate multiple cutting edges with several cutting conditions in the face milling process. It's revealed that high rotation of cutting tool provides high contribution for the quality of surface roughness on the product. The objective of the present study is to figure out the optimum parameters condition for selected control factor, that are cutting speed, depth of cut and feed. The experiment on CNC turning machine by using a carbide insert tool with AISI 1045 steel material was performed. The Taguchi method is applied to this study to gain optimization

\section{METHODS}

Taguchi's robust design is a statistical methodology for the application of design experiments [11]. Taguchi method using experimental design for a) product design/process makes it robust to environment situation, b) robust to variation, and c) reducing variation near to target value. This design provides a powerful and efficient technique for designing products that operate consistently and optimally over a variety of conditions. As a robust design, the primary goal of the Taguchi method is to find factor settings that minimize response variation, while adjusting the process on target.

\subsection{Orthogonal Array}

The experiment with Taguchi design is using a partial factorial experiment, in which the number of factor combinations is reduced into a special set. There is 18 standard set designed by Taguchi, namely orthogonal array (OA). The OA provides a set of good balances with minimum experimental runs. Three factors with three-level respectively were used in this study. Therefore, based on the OA standard 9 runs $\left(\right.$ L9 $3^{3}$ ) experiment performed with different factor combinations, as shown in table 1.

Table 1. OA with L9 $3^{3}$

\begin{tabular}{cccc}
\multicolumn{5}{c}{ Table 1. OA with L9 $3^{3}$} \\
\hline Run & Factor 1 & Factor 2 & Factor 3 \\
\hline 1 & 1 & 1 & 1 \\
2 & 1 & 2 & 2 \\
3 & 1 & 3 & 3 \\
4 & 2 & 1 & 2 \\
5 & 2 & 2 & 3 \\
6 & 2 & 3 & 1 \\
7 & 3 & 1 & 3 \\
8 & 3 & 2 & 1 \\
9 & 3 & 3 & 2 \\
\hline
\end{tabular}

\subsection{Quality Characteristic}

A loss function in the Taguchi method is defined to calculate the deviation of experimental yield and desired yield. Taguchi suggests the use of loss function to measure the achievement characteristic deviating from the desired yield. The objective of the robust design is to minimize the loss function. Furthermore, the loss function is transformed into a signal to noise $(\mathrm{S} / \mathrm{N})$ ratio. The $\mathrm{S} / \mathrm{N}$ ratio is used as a measurable value instead of standard deviation, as the mean decreases, the standard deviation also decreases and vice versa. Simply, the standard deviation can't be reduced first and the mean moved to the target.

Some uncontrollable factors (noise factors) could exist during the experiment. By Taguchi design, a measure of robustness was used to identify the control factors that minimize variability in the product by reducing the effects on noise factors. Taguchi introduced the communication-engineering concept in his design. When the input signal is given, the output signal $y$ would be generated by the system. If there were no noise come in, the output $y$ would be stable and has no variation. Yet, if the noise comes in, the output $y$ will not be 
consistent and could be varied. To achieve the fine communication mechanism, the noise effect should in minimum influence in comparison with the output $y$. Therefore, the maximum $\mathrm{S} / \mathrm{N}$ ratio is equivalent to reduce quality loss function. There are three specifics typical of the performance characteristic in $\mathrm{S} / \mathrm{N}$ ratio analysis, that are larger is better, nominal the best, and smaller is better, respectively. The formula to figure out the characteristics are:

1. Characteristic nominal the best:

$$
\frac{S}{N}=10 \log \left(\frac{\mu^{2}}{\sigma^{2}}\right)
$$

2. Characteristic smaller is better:

$$
\frac{S}{N}=-10 \log \left(\frac{1}{n} \sum_{i=1}^{n} y_{i}{ }^{2}\right)
$$

3. Characteristic larger is better:

$$
\frac{S}{N}=-10 \log \left(\frac{1}{n} \sum_{i=1}^{n} \frac{1}{y_{i}^{2}}\right)
$$

\subsection{Design of Experiment}

The experiment is conducted on CNC turning type CKE $6140 \mathrm{Z}$ with FANUC controller. Cutting fluid was supply to the tool during the turning process. The carbide insert tool clamped to the tool holder SDJCR 2020-11and AISI 1045 material with the initial diameter $\varnothing 20 \mathrm{~mm}$ used, machining length $l_{c} 150 \mathrm{~mm}$ in the axial direction. Material AISI 1045 is categorized as mild carbon steel with a carbon composition of $0.42-$ $0.50 \%$. Following are the mechanical properties of material AISI1045.

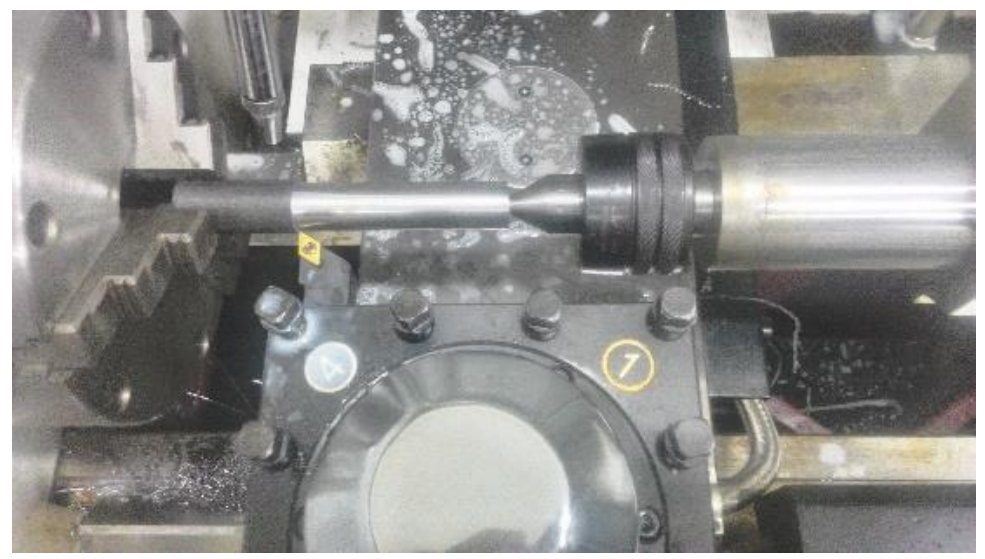

Figure 1: Turning process

Table 2: Mechanical properties on AISI1045 steel

\begin{tabular}{lc}
\hline Mechanical properties & Metric unit \\
\hline Carbon, C & $0.42-0.5 \%$ \\
Iron, Fe & $98.51-98.98 \%$ \\
Density & $7.87 \mathrm{~g} / \mathrm{cc}$ \\
Hardness, Brinell & 163 \\
Hardness, Rockwell B & 84 \\
Hardness, Vickers & 170 \\
Tensile Strength, Ultimate & $585 \mathrm{MPa}$ \\
Tensile Strength, Yield & $450 \mathrm{MPa}$ \\
Modulus of elasticity & $206 \mathrm{GPa}$ \\
Shear Modulus & $80.0 \mathrm{GPa}$ \\
\hline
\end{tabular}

Measuring the workpiece surface roughness used Mitutoyo SJ-210P surface tester. Three cutting condition parameters with three-level, respectively, as shown in the following table: 
Table 3 : Control factors and levels

\begin{tabular}{lccc}
\hline Factor & Level 1 & Level 2 & Level 3 \\
\hline Cutting speed, $v(\mathrm{~m} / \mathrm{mnt})$ & 70 & 90 & 110 \\
Depth of cut, $a(\mathrm{~mm})$ & 0.5 & 1 & 1.5 \\
Feed, $f(\mathrm{~mm} / \mathrm{rot})$ & 0.05 & 0.1 & 0.15 \\
\hline
\end{tabular}

\section{RESULTS AND DISCUSSION}

The experiment in the turning process with machining parameters is performed. Figure 2 illustrated the turning process on CNC turning machine. Then, measuring surface roughness with $R a$ parameter (arithmetic average of roughness value) performed 3 replications on each machined specimen. The data record is shown in table 4. Moreover, a lower $R a$ value indicates a fine result. Therefore, a smaller is better characteristic is select to meet the requirement.

Table 4 : Surface Roughness $R a$ of machined product with $\mathrm{S} / \mathrm{N}$ ratio

\begin{tabular}{|c|c|c|c|c|c|c|c|c|}
\hline \multirow{2}{*}{$\begin{array}{c}\text { Exp. } \\
\text { run }\end{array}$} & \multicolumn{3}{|c|}{ Control factor } & \multicolumn{4}{|c|}{ Measurements, $R a(\mu \mathrm{m})$} & \multirow[b]{2}{*}{$\mathrm{S} / \mathrm{N}$ ratio } \\
\hline & $\mathbf{v}$ & $\mathbf{a}$ & f & 1 & 2 & 3 & Mean & \\
\hline 1 & 70 & 0.5 & 0.05 & 1.91 & 1.85 & 1.70 & 1.82 & -5.22 \\
\hline 2 & 70 & 1 & 0.1 & 0.92 & 0.97 & 1.04 & 0.98 & 0.21 \\
\hline 3 & 70 & 1.5 & 0.15 & 2.19 & 2.23 & 2.28 & 2.23 & -6.98 \\
\hline 4 & 90 & 0.5 & 0.1 & 1.26 & 1.28 & 1.29 & 1.28 & -2.13 \\
\hline 5 & 90 & 1 & 0.15 & 1.66 & 1.67 & 1.70 & 1.67 & -4.47 \\
\hline 6 & 90 & 1.5 & 0.05 & 0.68 & 0.57 & 0.49 & 0.58 & 4.64 \\
\hline 7 & 110 & 0.5 & 0.15 & 1.76 & 1.78 & 1.79 & 1.78 & -5.00 \\
\hline 8 & 110 & 1 & 0.05 & 0.54 & 0.43 & 0.41 & 0.46 & 6.66 \\
\hline 9 & 110 & 1.5 & 0.1 & 1.21 & 0.66 & 0.52 & 0.80 & 1.40 \\
\hline
\end{tabular}

\subsection{Results}

The response table 5 and 6 shows the result of surface roughness $R a$ with and $\mathrm{S} / \mathrm{N}$ ratio value involved rank for each control factor. Based on the result data, revealed that the first rank for each factor, sequentially from feed, cutting speed and depth of cut for mean value and rank for $\mathrm{S} / \mathrm{N}$ ratio as well. Explanation about control factors to the mean of surface roughness and $\mathrm{S} / \mathrm{N}$ ratio illustrated in figure 3 and figure 4, respectively. Clear enough in figure 3, which control factors and levels provide low surface roughness. Likewise, figure.4 depict straightforward which control factor and level give large $\mathrm{S} / \mathrm{N}$ ratio.

Table 5 : Response table for Mean

\begin{tabular}{lccc}
\hline Level & Cutting speed, $\boldsymbol{v}$ & Depth of cut, $\boldsymbol{a}$ & Feed, $\boldsymbol{f}$ \\
\hline 1 & 1.6770 & 1.6256 & 0.9544 \\
2 & 1.1774 & 1.0367 & 1.0167 \\
3 & 1.0119 & 1.2041 & 1.8952 \\
Delta & 0.6652 & 0.5889 & 0.9407 \\
Rank & 2 & 3 & 1 \\
\hline
\end{tabular}

Table 6 : Response table for $\mathrm{S} / \mathrm{N}$ ratio

\begin{tabular}{lccc}
\hline Level & Cutting speed, $\boldsymbol{v}$ & Depth of cut, $\boldsymbol{a}$ & Feed, $\boldsymbol{f}$ \\
\hline 1 & -3.9990 & -4.1149 & 2.0275 \\
2 & -0.6540 & 0.7976 & -0.1752 \\
3 & 1.0203 & -0.3152 & -5.4849 \\
Delta & 5.0193 & 4.9125 & 7.5125 \\
Rank & 2 & 3 & 1 \\
\hline
\end{tabular}




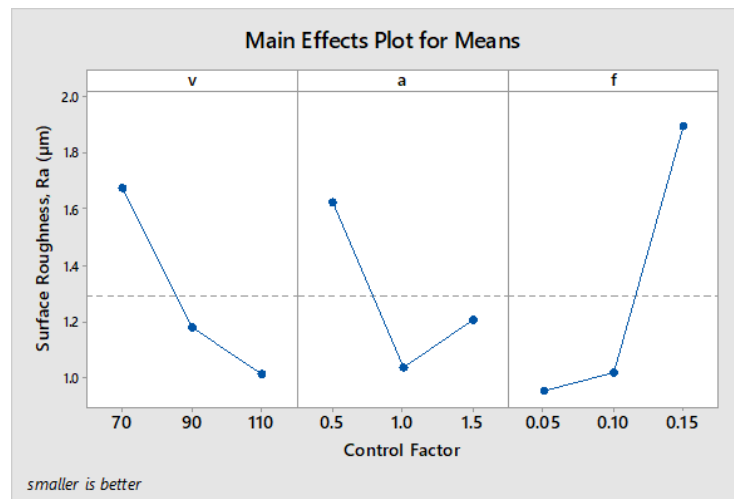

(a)

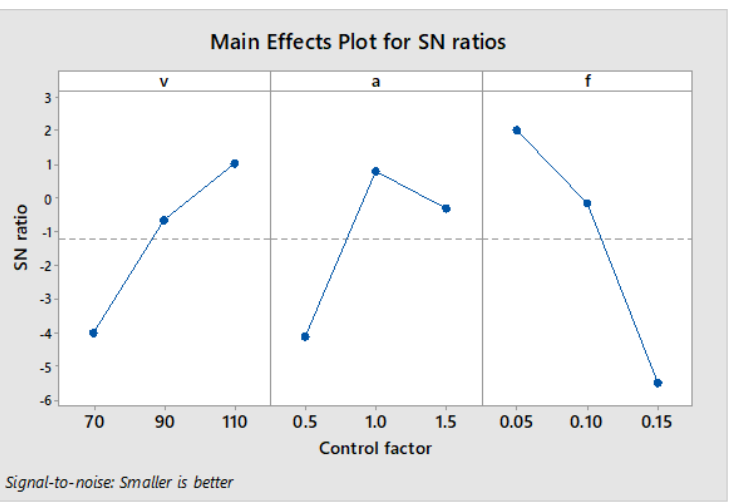

(b)

Figure 4: (a) Main effect plot for mean and (b) Main effect plot for S/N ratio

\subsection{Analysis of Variance (ANOVA)}

ANOVA is used to estimate the contribution for each factor quantitatively. This procedure describes how significant the effect of each control factor is toward the response value, surface roughness $R a$. Calculation of ANOVA, first, compute the sum of square (SS) and the sum of square total (SST):

$$
\begin{aligned}
& S S=\frac{k}{N \times n} \sum_{t=1}^{k} T_{t}^{2}-\frac{T^{2}}{N \times n} \\
& \mathbf{S S}_{\mathbf{T}}=\sum_{\mathbf{i}=\mathbf{1}}^{\mathbf{N}} \sum_{\mathbf{j}=\mathbf{1}}^{\mathbf{n}} \mathbf{y}_{\mathbf{i j}}^{\mathbf{2}}-\frac{\mathbf{T}^{\mathbf{2}}}{\mathbf{N} \times \mathbf{n}}
\end{aligned}
$$

The Mean Square (MS) is obtained from dividing the SS by degree of freedom (df). Every column of the orthogonal array defined that $k$ levels, and for each level $t$, the total sum of represented by $T$. Number of experiments is $\mathrm{N}$, and the number of replicates is $n$. Table 7, ANOVA for mean, revealed that factor feed $f$ provides the highest contribution about $53.73 \%$ to the result.

Table 7 : ANOVA for mean

\begin{tabular}{lllllll}
\hline Source & Df & Seq.SS & Contribution & Adj.SS & Adj.MS & F-value \\
\hline $\mathrm{v}$ & 2 & 0.7195 & $23.28 \%$ & 0.7195 & 0.35975 & 4.55 \\
$\mathrm{a}$ & 2 & 0.5525 & $17.87 \%$ & 0.5525 & 0.27623 & 3.49 \\
$\mathrm{f}$ & 2 & 1.6607 & $53.73 \%$ & 1.6607 & 0.83033 & 10.49 \\
Error & 2 & 0.1583 & $5.12 \%$ & 0.1583 & 0.07913 & \\
Total & 8 & 3.0909 & $100.00 \%$ & & & \\
\hline
\end{tabular}

\subsection{Discussion}

A series of experiments on CNC turning and examination of surface quality is conducted. Based on the data record, response table of mean $-\mathrm{S} / \mathrm{N}$ ratio, main effect plot and ANOVA revealed that the factor feeding $f$ is most contribute to the result with more than $50 \%$, followed by cutting speed $23.28 \%$ and depth of cut $17.87 \%$, respectively. Meanwhile, the optimum setting was achieved by cutting speed $v 110 \mathrm{~m} / \mathrm{mnt}$; depth of cut $a 1 \mathrm{~mm}$, and feed $f 0.05 \mathrm{~mm} /$ rot. This optimum parameter setting on CNC turning generates the lowest surface roughness that is $0.54 \mu \mathrm{m}$. Meanwhile, the highest $\mathrm{S} / \mathrm{N}$ ratio obtains with combination $v=110, a=1$, and $f=0.05$, the same factor combination with response table of the mean. The Highest S/N ratio of 6.66 indicates minimizing loss function during the machining process. The optimum setting achieved on CNC turning is a prediction. One more stage should be to make sure about the result that is confirmation experiment.

Table 8. Prediction of optimum parameter setting

\begin{tabular}{lll}
\hline Control factor & Level & Ra; $\boldsymbol{\mu m}$ \\
\hline Cutting speed, $v$ & $3: 110 \mathrm{~m} / \mathrm{mnt}$ & \\
Depth of cut, $a$ & $2: 1 \mathrm{~mm}$ & $0.46 \mu \mathrm{m}$ \\
Feeding, $f$ & $1: 0.05 \mathrm{~mm} / \mathrm{rot}$ & \\
\hline
\end{tabular}

Journal homepage: http://teknomekanik.ppj.unp.ac.id

DOI: https://doi.org/10.24036/teknomekanik.v4i1.11072 


\subsection{Confirmation Experiment}

Confirmation experiment conducted after the prediction of optimum parameters setting obtained. The machining process is carried out with level 3 of spindle speed $v$; level 2 of cutting depth $a$; and level 1 of feeding $f$. The following is the surface roughness value after the confirmation experiment was performed.

Table 9. Confirmation Experiment result

\begin{tabular}{clcc}
\hline Control factor & Level & Ra; $\boldsymbol{\mu m}($ final $)$ & Mean; $\boldsymbol{\mu m}$ \\
\hline$v$ & $3: 110 \mathrm{~m} / \mathrm{mnt}$ & 0.39 & \\
$a$ & $2: 1(\mathrm{~mm})$ & 0.61 & $\mathbf{0 . 5 1}$ \\
$f$ & $1: 0.05(\mathrm{~mm} / \mathrm{rot})$ & 0.54 & \\
\hline
\end{tabular}

\section{CONCLUSION}

The simple and practical way of the Taguchi method is carried out to achieve the combination of the optimum factors. Low cost, reduce machining time and efficiency experiment provide by using Taguchi approach. Some conclusions could be drawn from this study:

1. The lowest parameter of feed-in CNC turning brought the most significant effect toward the surface quality of the product. Then, following by higher cutting speed and low depth of cut.

2. A combination of lower feed with high rotation of the main spindle is recommended to the machining operator in terms of achieving fine surface quality. This setting combination usually applies in the finishing stage to obtain a good quality product.

3. The carbide tool is a workable cutting tool to mid carbon steel material.

\section{ACKNOWLEDGEMENTS}

Million thanks to the Lembaga Penelitian dan Pengabdian Masyarakat Universitas Negeri Padang for funding this study activity. Aside from that, thanks a lot to Mechanical Engineering Dept. Official and laboratory for the permission to use the equipment and tools.

\section{REFERENCES}

[1] VD Patel, AH Gandhi. Analysis and Modelling of Surface Roughness Based on Cutting Parameters and Tool Nose Tadius in Turning of AISI D2 Steel Using CBN Tool, Measurement 2019; 138: 34-38.

[2] Palanikumar K, Mata F, Davim JP. Analysis of Surface Roughness Parameter in Turning of FRP Tubes by PCD Tool. Journal of Materials Processing Technology 2008; 205: 469-474.

[3] Fratila D, Caizar C. Application of Taguchi Method to Selection of Optimal Lubrication and Cutting Condition in Face Milling of AlMg $\mathrm{Al}_{3}$. Journal of Cleaner Production 2011; 19: 640-645.

[4] Asilturk I, Akkus H. Determining the Effect of Cutting Parameters on Surface Roughness in Hard Turning Using the Taguchi Method. Measurement 2011; 44: 1697-1704.

[5] Syahri B, Prasetya F, Refdinal R, et al. Effect of cutting speed on milling process on surface roughness of ST-37 steel material workpiece. Invotek 2021; 21: 19-26.

[6] Kosaraju S, Chandraker S. Taguchi Analysis on Cutting Force and Surface Roughness in Turning MDN350 Steel. Materials Today: Proceedings 2 2015; 3388-3393.

[7] Masmiati N, Ahmed AD, Sarhan. Optimizing Cutting Parameters in Inclined End Milling for Minimum Surface Residual Stress - Taguchi Approach. Measurement 2015; 60: 267-275.

[8] Mandal N, Doloi B, Mondal B, Das R. Optimization of Flank Wear Using Zirconia Taoughned Alumina (ZTA) Cutting Tool: Taguchi Method and Regression Analysis. Measurement 2011; 44: 2149-2155.

[9] Das MK, Kumar K, et.al. Optimization of Material Removal Rate in EDM Using Taguchi Method. Advanced Materials Research 2013; 626: 270-274.

[10] Baharudin BTHT, et al. Experimental Investigation of HSS Face Milling to AL6061 using Taguchi Method. Procedia Engineering 2012; 50: 933-941

[11] Yang K, El-Haik B. Design for Six Sigma: A Roadmap for Product Development. McGraw-Hill 2003, USA, 2003.

\section{NOMENCLATURE}

$\begin{array}{ll}R a & \text { Roughness average of surface mesured in micron } \\ \mathrm{S} / \mathrm{N} \text { ratio } & \text { Ratio of signal to noise } \\ v & \text { cutting speed in } \mathrm{m} / \mathrm{mnt}\end{array}$

Journal homepage: http://teknomekanik.ppj.unp.ac.id

DOI: https://doi.org/10.24036/teknomekanik.v4i1.11072 
$f \quad$ feeding in $\mathrm{mm} / \mathrm{rot}$

a depth of cut in mm

L9 number of run the experiment (9 times) 